Supplement of Biogeosciences, 18, 207-228, 2021

https://doi.org/10.5194/bg-18-207-2021-supplement

(C) Author(s) 2021. This work is distributed under

the Creative Commons Attribution 4.0 License.

(c) (1)

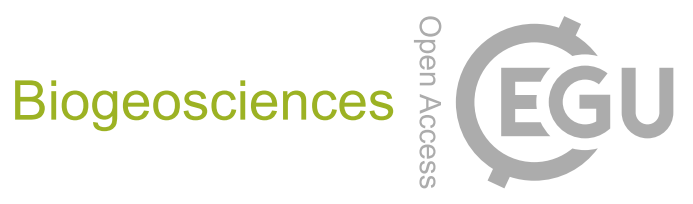

Supplement of

\title{
Fire and vegetation dynamics in northwest Siberia during the last 60 years based on high-resolution remote sensing
}

\section{Oleg Sizov et al.}

Correspondence to: Ekaterina Ezhova (ekaterina.ezhova@helsinki.fi)

The copyright of individual parts of the supplement might differ from the CC BY 4.0 License. 


\section{Supplementary material}
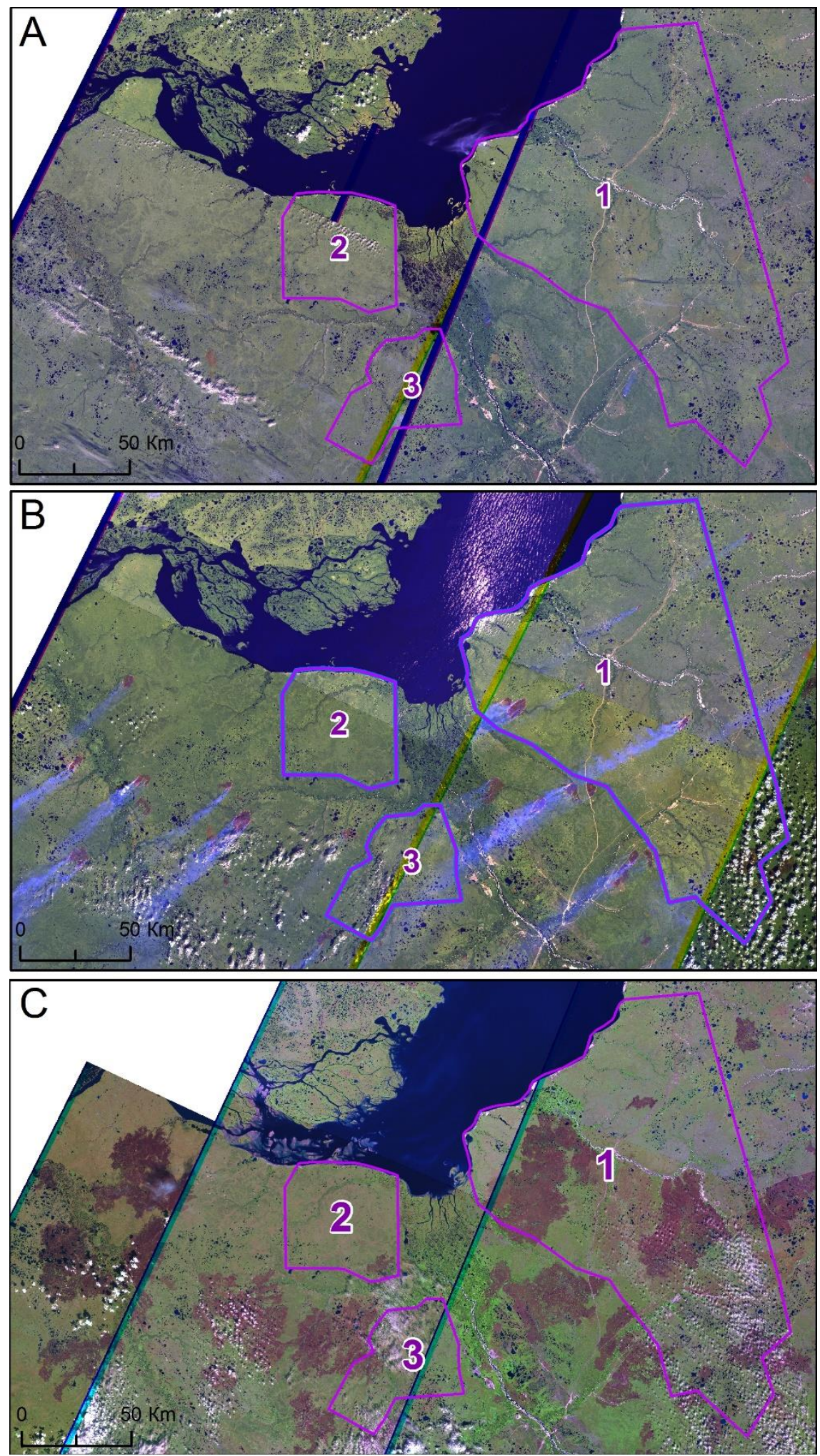

Fig. S1. Illustration of the major fires of 1990 in Landsat 5 mosaics from 1990/1991. A - before fires (15 June - 12 July 1990), B - active fires (17, 18, 28 July 1990), C - after fires (22 July - 30 August 1991). (C) Microsoft. 


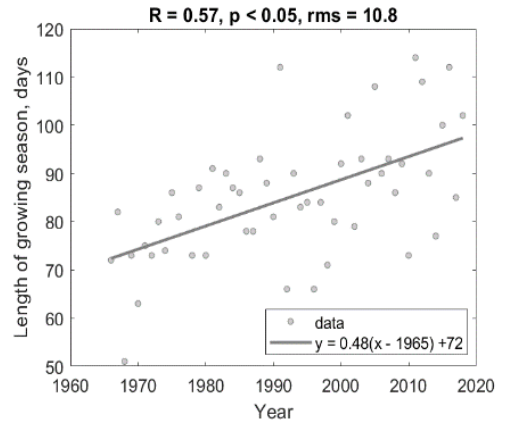

(a)

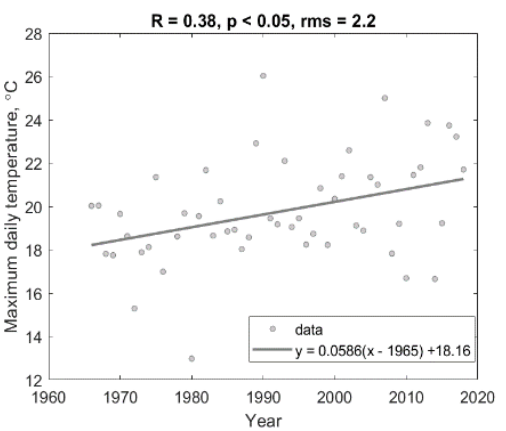

(d)

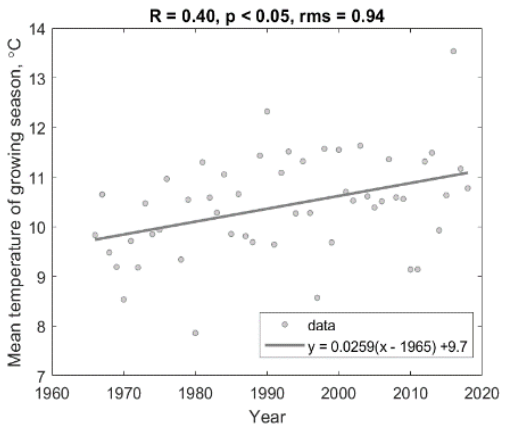

(b)

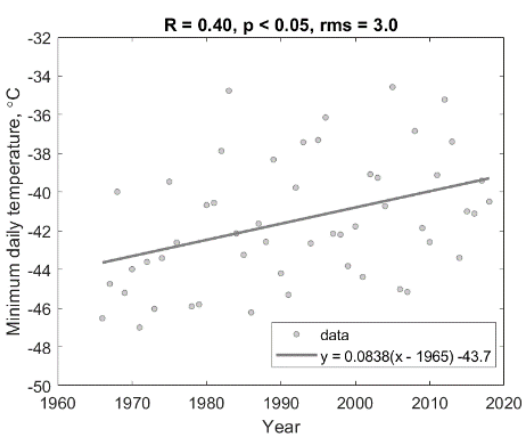

(e)

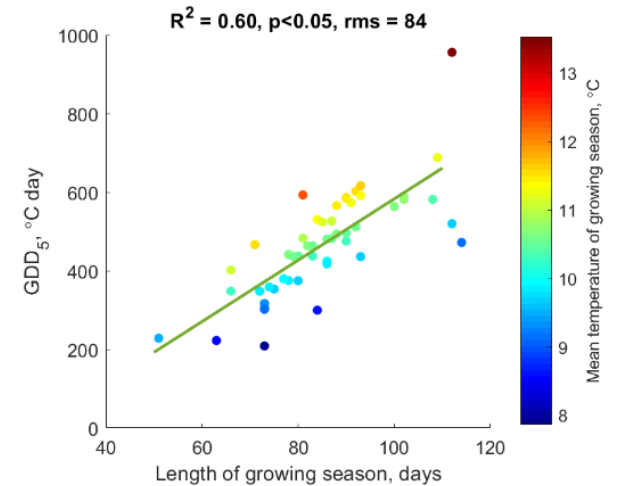

(c)

Fig. S2. Long term-trends, Novy Port: length of growing season (a), mean temperature of growing season (b) minimum daily temperature (d), maximum daily temperature (e); correlation of growing degree-days with the length of growing season (c), color scale - mean temperature of growing season.

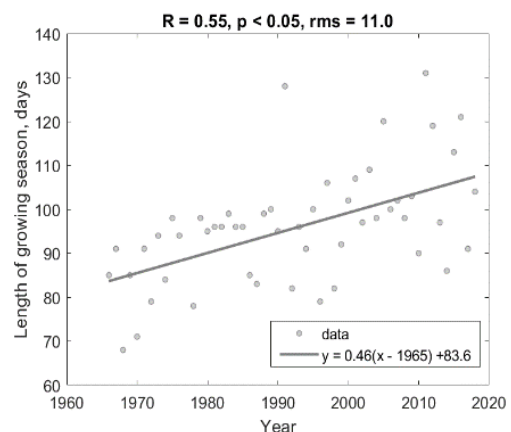

(a)

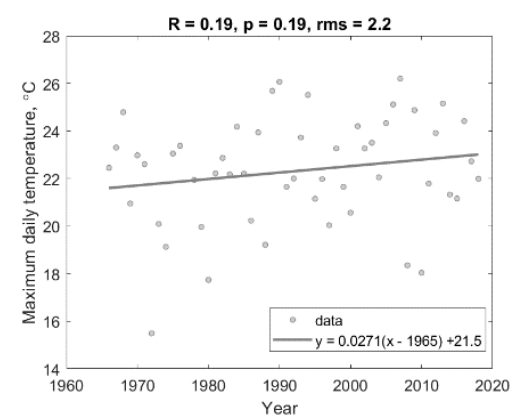

(d)

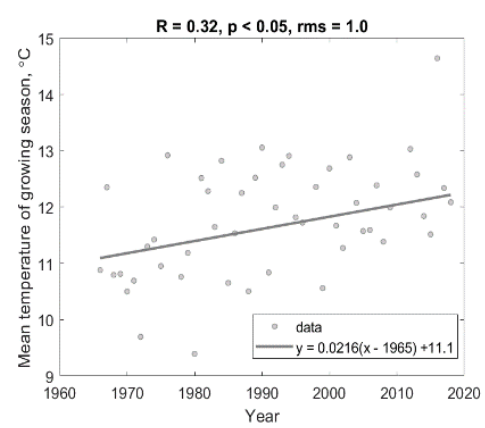

(b)

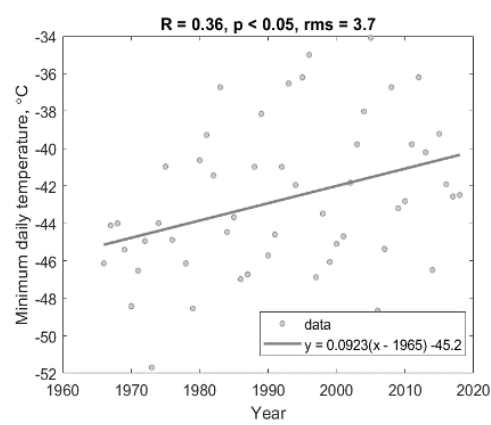

(e)

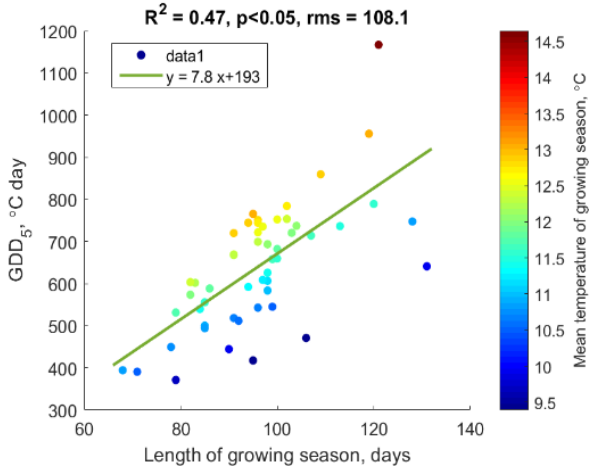

(c)

Fig. S3. Same as Fig. S2, for Nyda. 


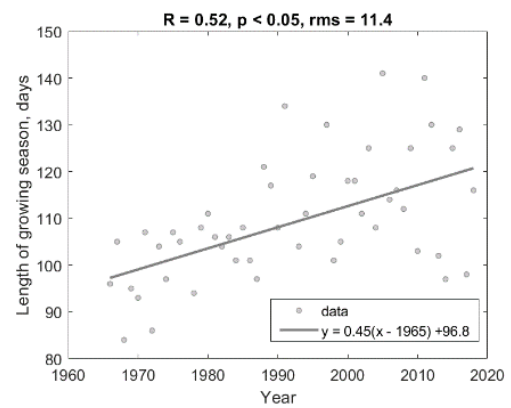

(a)

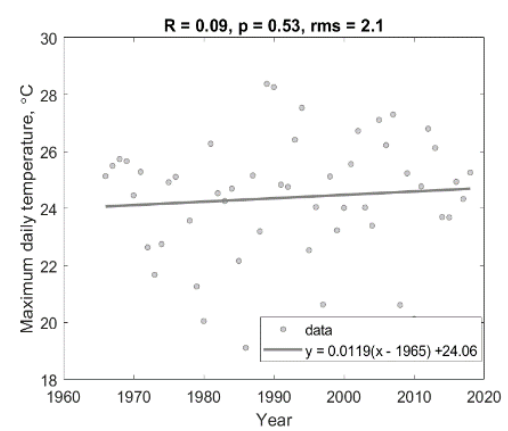

(d)

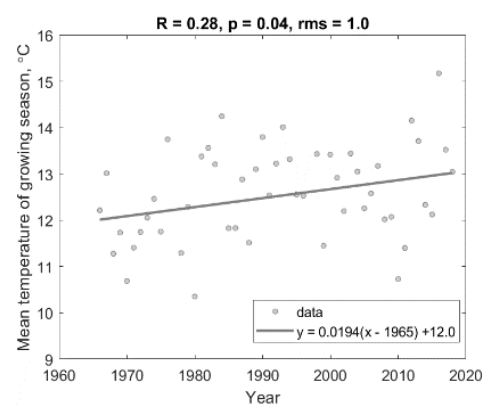

(b)

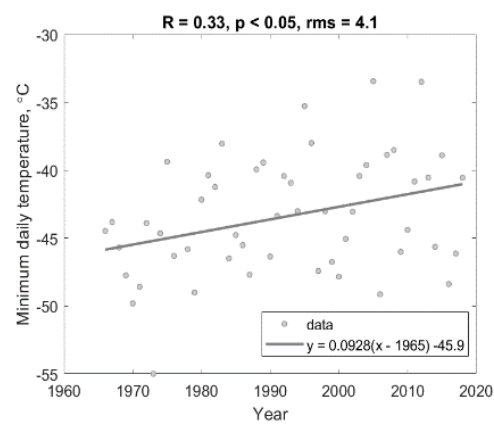

(e)

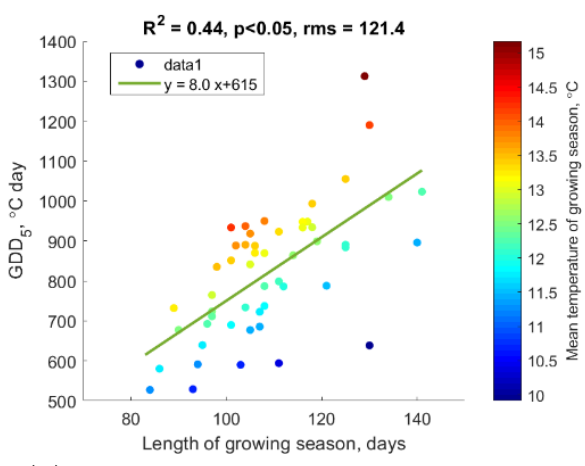

(c)

Fig. S4. Same as Fig. S2, for Nadym.
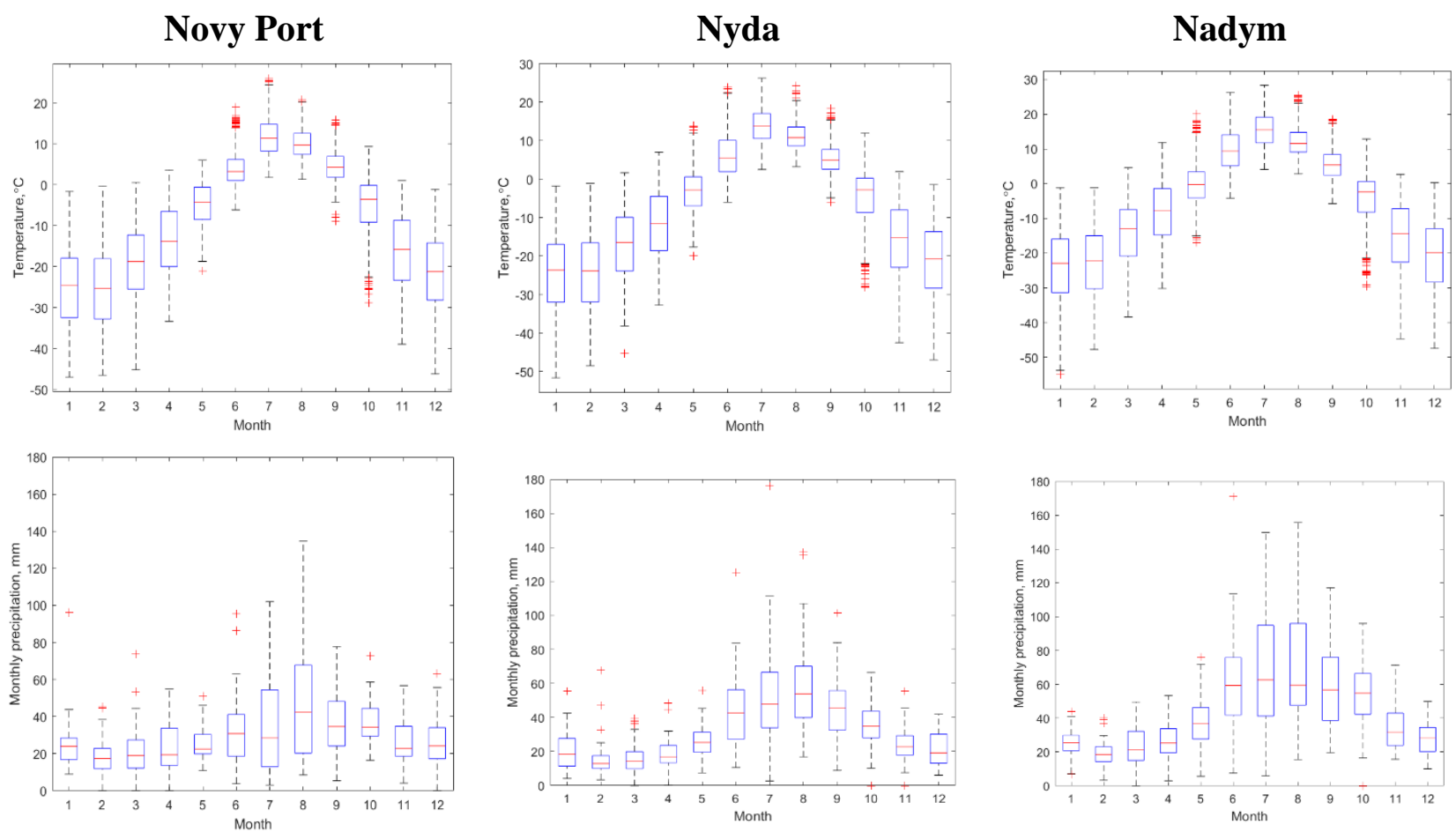

Fig. S5. Seasonal cycles of monthly temperature and precipitation over 1966-2010. Red risks denote median values, bottom and top edges of boxes are 25 th and 75 th percentiles. 


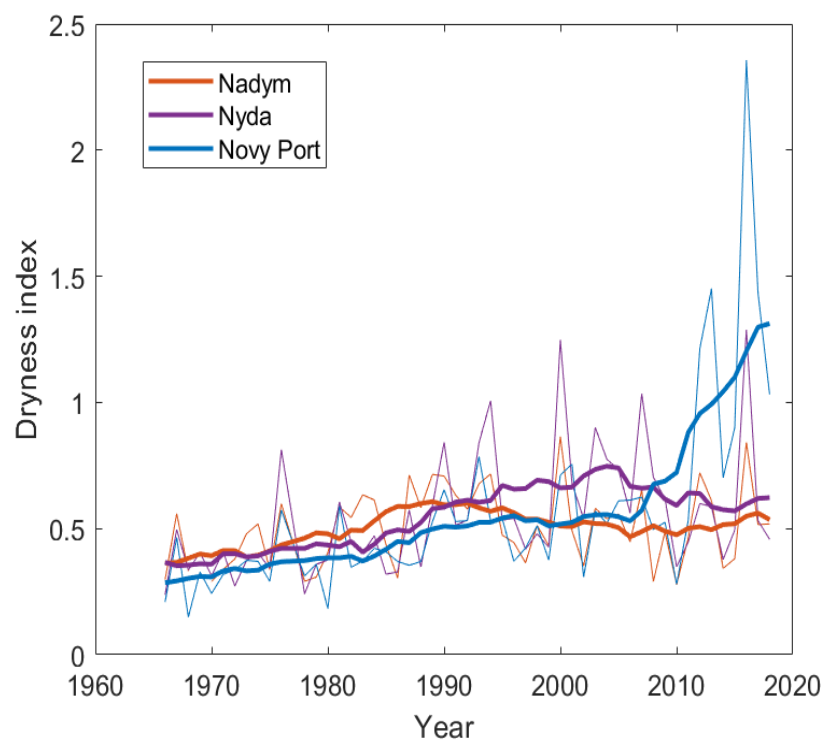

Fig. S6. Dryness index, the ratio between potential evaporation and precipitation.

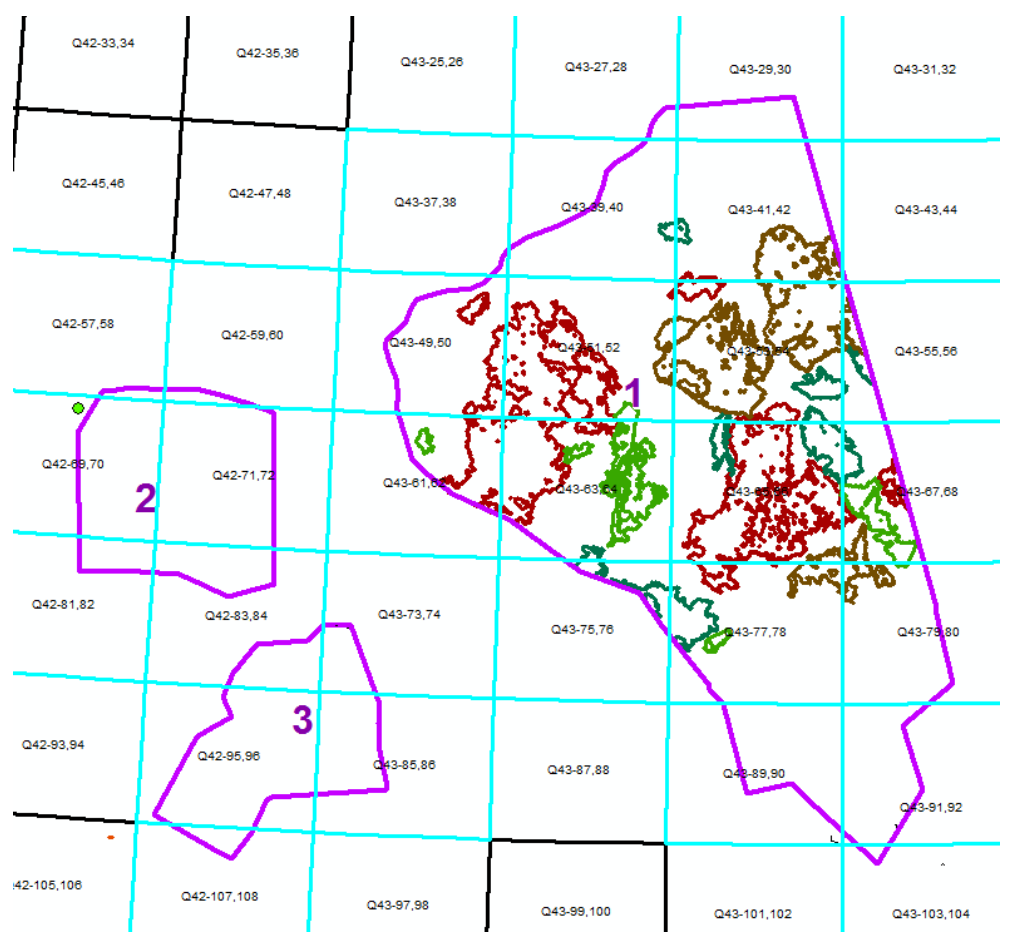

Fig. S7. Coverage of the study areas by separate sheets of the topographic map. 
Table S1. Best fit parameters of the NDVI distributions in Fig. $7 b$ by the function $A=A_{1} \exp \left(-\frac{\left(N D V I-N D V I_{\max , 1}\right)^{2}}{2 \sigma_{1}^{2}}\right)+A_{2} \exp \left(-\frac{\left(N D V I-N D V I_{\max , 2}\right)^{2}}{2 \sigma_{2}^{2}}\right)$.

\begin{tabular}{|l|l|l|l|l|l|l|}
\hline Year & $\mathrm{A}_{1}, \mathrm{~km}^{2}$ & $\mathrm{NDVI}_{\max 1}$ & $\sigma_{1}$ & $\mathrm{~A}_{2}, \mathrm{~km}^{2}$ & $\mathrm{NDVI}_{\max 2}$ & $\sigma_{2}$ \\
\hline $1968+1988$ & 0.28 & 0.64 & 0.07 & 0.12 & 0.77 & 0.04 \\
\hline 2001 & 0.85 & 0.62 & 0.04 & 0.40 & 0.71 & 0.06 \\
\hline 2018 & 0.50 & 0.54 & 0.07 & - & - & - \\
\hline Background & 0.65 & 0.59 & 0.06 & - & - & - \\
\hline
\end{tabular}

